\title{
HRR Field of a Moving Crack, an Experimental Analysis
}

MAHYAR S DADKHAH and ALBERT S. KOBAYASHI

University of Washington, Department of Mechanical Engineering, FU-10, Seattle, Washington 98195, USA

\section{ABSTRACT}

An improved moiré interferometry was used to record simultaneously both the vertical and An improved displacements associated with stable crack growth in uniaxially and biaxially loaded 2024-0 and 2024-T3 aluminum, single edge notched specimens. For stable crack growth up to $5 \mathrm{~mm}$, the vertical displacement field showed the dominance of the HRR field but the HRR field was detected in the horizontal displacement only at the initial stage of loading. The far and near field J-integrals were path independent and yielded the correct crack tip displacements only at the initial stage of loading in the horizontal direction and at the terminal stage of loading in the vertical displacement field. The preliminary results indicate that $\mathrm{secharacterzation}$ arials for this specimen configuration.

\section{KEYWORDS}

HRR field; moiré interferometry; biaxial; J-integral; J-resistance; ductile fracture; J-dominance region; aluminum

\section{INTRODUCTION}

For the past two decades, an enormous amount of research and development efforts have been For the past wo dectile engineering materials expended in jus ox From the ves optile fracture criteria, such as crack opening displacement (COD) and crack the propo of far field J-value, which under certain conditions represents the crack tip J-value through Rice's path independence proof (Rice, 1968). In contrast, the COD and the CTOD pose ung experimental challenges. The asymptotic crack tip solution, which justifies Rice's J-integral Rosengren (1968) and is commonly referred to as the HRR field. 
The extent of this HRR field has been studied numerically by McMeeking and Parks (1979) Shih and German (1981) and Shih (1985) for a single-edged crack beam under bending and center crack plate under uniaxial tension. Shih (1985) summarizes the findings of these three condition to exist.

For an incompressible fully plastic power hardening material, the uniaxial strain $\varepsilon$ is related to uniaxial stress $\sigma$ by

$$
\frac{\varepsilon}{\varepsilon_{o}}=\alpha\left(\frac{\sigma}{\sigma_{0}}\right)^{n}
$$
For a crack tip field under pure bending, the $J$ integral characterizes the plane-strain crack tip

$$
\mathrm{b}>25 \mathrm{~J} / \sigma_{o}
$$

Likewise condition for a plane strain crack tip field under pure tension is

$$
\mathrm{b}>200 \mathrm{~J} / \sigma_{o}
$$

Here $b$ is the characteristic size parameter which is the remaining ligament between the crack tip and the edge of the specimen. $\varepsilon_{o}$ and $\sigma_{o}$ are often referred to as the yield strain and yield stress, respectively where $\varepsilon_{o}=\sigma_{o} / \mathrm{E}$ and $\mathrm{E}$ is the modulus of elasticity. $\alpha$ and $\mathrm{n}$ are experimentally determined parameters for the power hardening law.

Although the path independence of the J-integral is valid only for nonlinear elastic solids or deformation theory of plasticity, Shih et al. (1979), through numerical analysis, found that this restriction could be relaxed for small crack extension of the order of $5 \mathrm{~mm}$. To the writers best knowledge, comparable experimental analysis on the path independence of the J-integra or on the validity of the previously mentioned J-dominance criteria under crack extension does not exist. Chiang et al. (1986) has shown that in blunt notched 2024-0 and 6061-T6 aluminum tremely small strip region, which excludes the egion immediately adjacent to the notch tip.

The purpose of this paper is to provide experimental analyses of the above J-dominance crite accompanying a rapidly propagating crack in a ductile material.

\section{EXPERIMENTAL PROCEDURE}

The vertical and horizontal displacement in uniaxially and biaxially loaded 2024-0 and 2024-T3 aluminum, single-edged notched plate were determined by an improved moiré interferometry. Figure 1 shows the specimen configuration which was loaded on a special testing machine (Hawong et al., 1987). Figures $2 \mathrm{a}$ and $2 \mathrm{~b}$ show the uniaxial stress-strain relations in the vertical direction for the 2024-0 and 2024-T3 aluminum, respectively which were used in this study. Also shown are the two parameters for the corresponding power hardening relations. Similar relations in the horizontal directions were determined for the two aluminum plates and were found to be within 5\% of the experimental data shown in Fig. 2 .

The improved moiré interferometry consists of a beam splitter and a prism which records simultaneously the vertical and horizontal displacements in a single frame (Dadkhah et al., 1988). This method removes the approximation, which was necessary in previous studies

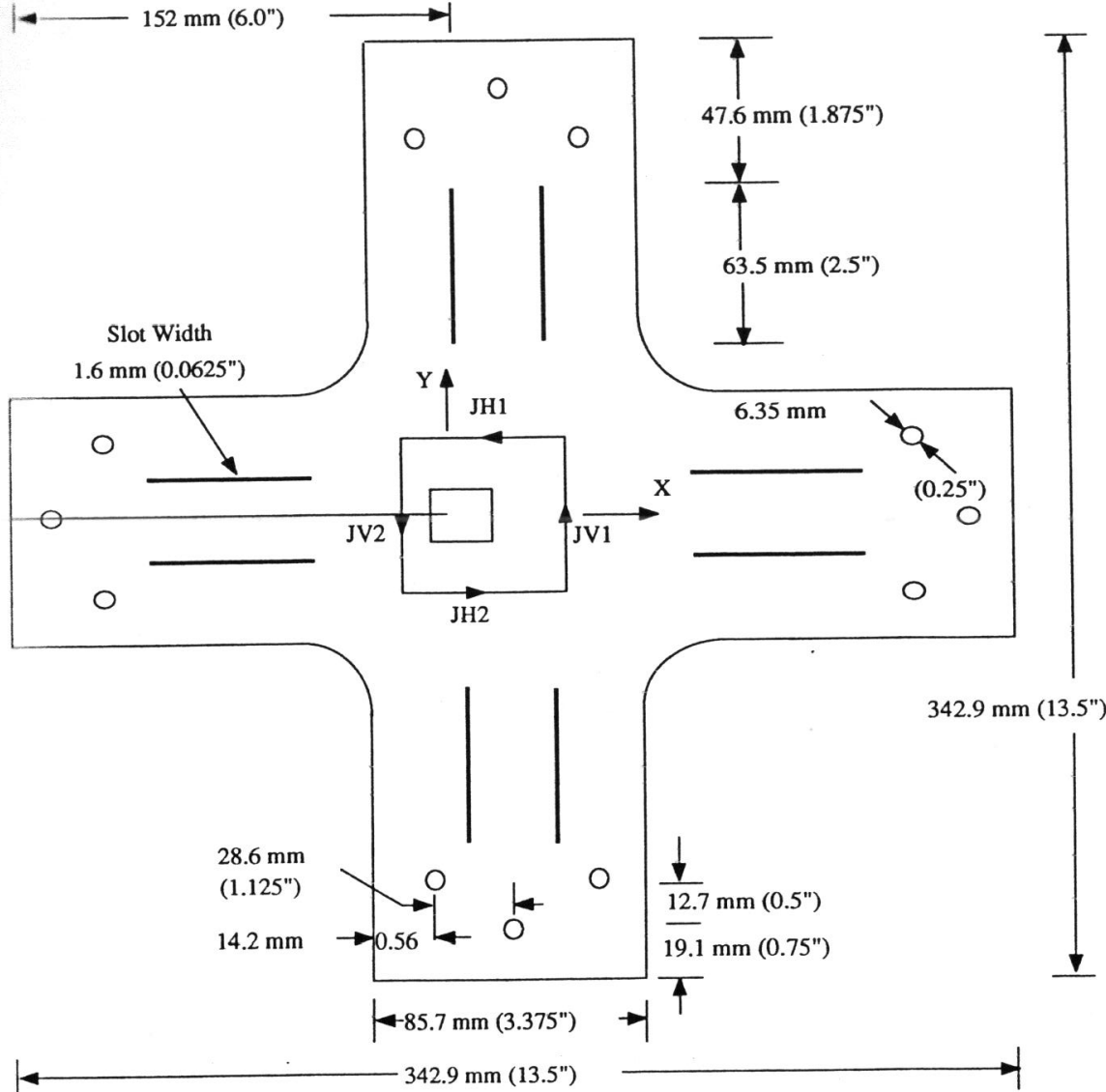

Fig. 1. Specimen Configuration and J-integral Paths

(Kang, et al. 1987, 1988) in the J-estimation. It is conducive for high speed photographic recording of the transient moiré fringes Fig. 1 associated with a rapidly propagating crack. For camera.

An AST Turboscan Digitizer and a Macintosh II computer were used to digitize the photographically recorded moiré fringes. A software was developed to compute the three strom coded displacement field. These strain components were used as shown in Fig. 1 (Dadkhah et al., 1988). 


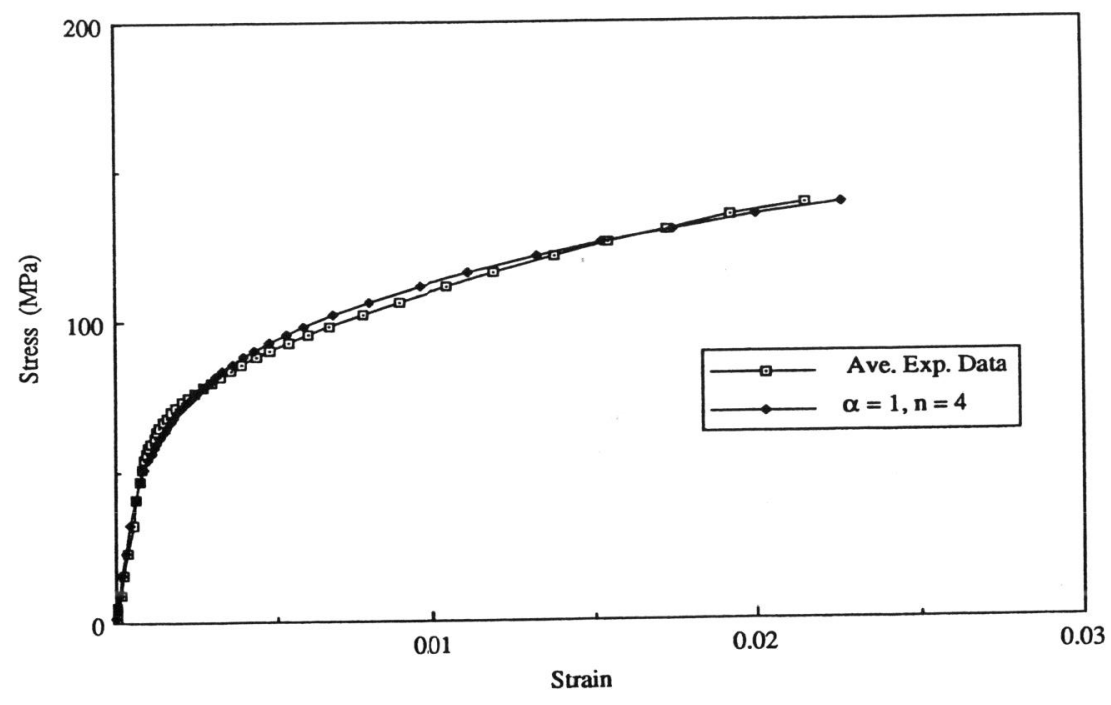

Fig. 2a. Uniaxial Stress-Strain Curve for 2024-0.

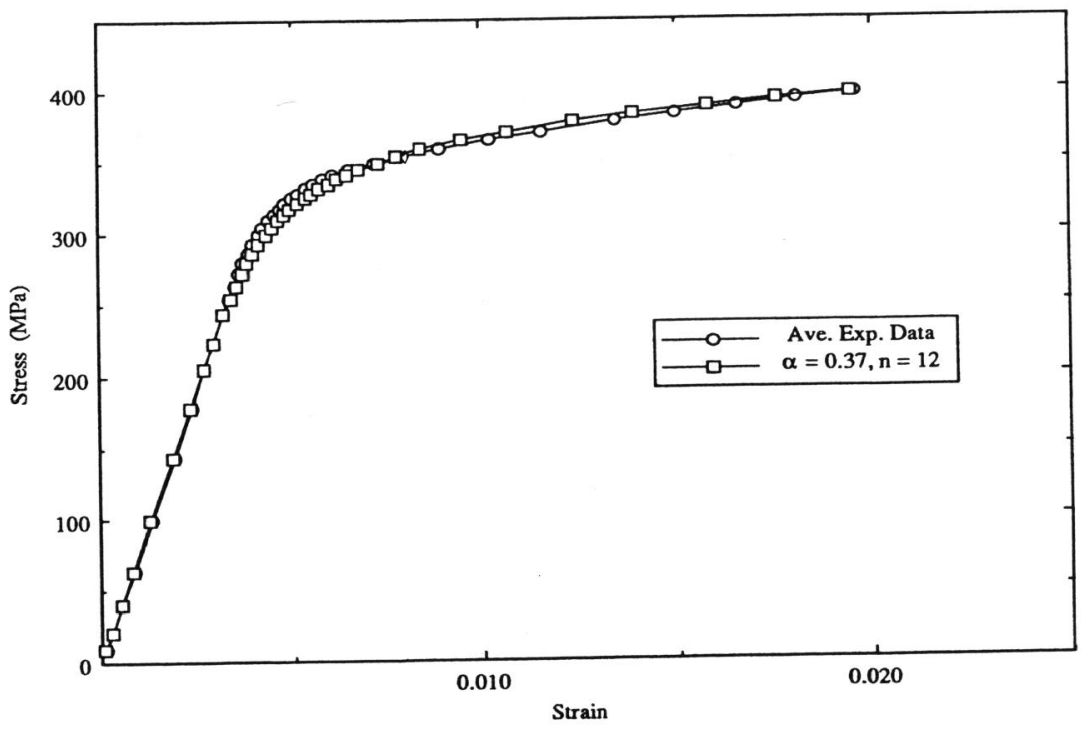

Fig. 2b. Uniaxial Stress-Strain Curve for 2024-T3.
RESULTS

The 2024-0 and 2024-T3 aluminum specimens were loaded uniaxially, i.e., at a biaxial ratio B $=0$, and biaxially with the horizontal load being twice the vertical load or $\mathrm{B}=2$. Table 1 shows the test matrix of this limited study together with the maximum crack extensions biaxially loaded $(\mathrm{B}=2)$ 2024-0 aluminum specimen.

Table 1. Test Matrix

\begin{tabular}{|c|c|c|}
\hline \multirow{2}{*}{$\begin{array}{c}\text { Biaxial } \\
\text { Load Ratio }\end{array}$} & $2024-\mathrm{T} 3$ & $2024-0$ \\
\hline $\mathrm{B}=0$ & \multicolumn{2}{|c|}{ Max. Crack Extension (mm) } \\
\hline $\begin{array}{c}3 \\
\mathrm{MD031687}\end{array}$ & $\begin{array}{c}1.34 \\
\text { MD050288 }\end{array}$ \\
\hline $\mathrm{B}=1$ & $\begin{array}{c}5.6 \\
\mathrm{MD} 102687\end{array}$ & \\
\hline $\mathrm{B}=2$ & $\begin{array}{c}4 \\
\mathrm{MD} 101987\end{array}$ & $\begin{array}{c}2.2 \\
\mathrm{MD} 050388\end{array}$ \\
\hline
\end{tabular}

Figures $4 \mathrm{a}$ and $4 \mathrm{~b}$ show typical moire fringes, i.e., the vertical displacement, $\mathrm{v}$, and the horizontal displacement, $\mathrm{u}$, for the biaxially loaded 2024-0 aluminum specimen. Also shown are typical integration contours used for the J-integral determination. The J values obtained along these contours are shown in Table 2 . Pah independen scatter in the J-values, is noted. Similar results were noted in the other four tests.

Figures 5 and 6 show typical log-log plots of the v- and u-displacement fields obtained from . Alstance $r$ of the moire fringes. Also shown are the log-log plots of displacement of $\theta=45^{\circ}$. The HRR field requ these plots indicate requires that this slope be $1 /(n+1)$, Which is 0.2 fhich later changed to an HRR field as the that the $v$-field exhibited terminal load was approached. The u-field, on the on non-linear zone at load exceeding 2600 (N). A similar trend was noted in the other three tests.

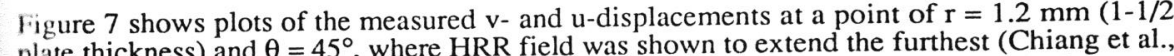
1086), with inceasing applied load. Also shown are the corresponding u- and v-displacement fields for the LEFM and HRR fields at the same location. The displacements for the HRR field were calculated by using the average J-integral values obtained through contour integrations of the moiré data. The corresponding displacement field for the LEFM crack tip were obtained by the equivalent plane-stress stress intensity factor computed from these J-integral values. A total of 34 numbers of log-log plots of the u-and v-fields were evaluated to arrive at the conclusion that only the v-field exhibited the HRR field through the loading and stable crack growth process.

The results are summarized in Fig. 8 which shows the J-resistance curve of this 2024-0 specimen for $\mathrm{B}=0$ and 2 . Also shown are the approximate J-integral values, which were reported by Kang et al. (1988), for the same material but for a much smaller specimen. These

AFR-1-X 
Table 2. J-integral Values Under Stable Crack Growth in 2024-0 Aluminum Specimen MD050388, B $\approx 2.0$.

\begin{tabular}{|c|c||c|c||l|}
\hline \multirow{2}{*}{ Load in X $(\mathrm{N})$} & \multirow{2}{*}{ Load in $\mathrm{Y}(\mathrm{N})$} & \multicolumn{2}{|c|}{$\mathrm{J}(\mathrm{kPa}-\mathrm{m})$} & $\begin{array}{c}\Delta \mathrm{a} \\
(\mathrm{mm})\end{array}$ \\
\cline { 3 - 4 } & & Contour 1 & Contour 2 & \\
\hline 4066 & 2086 & 4.0 & 3.8 & 0.14 \\
\hline 5489 & 2896 & 11.0 & 10.5 & 0.6 \\
\hline 5591 & 3305 & 18.1 & 18.4 & 0.85 \\
\hline 5845 & 3888 & 31.0 & 29.0 & 1.37 \\
\hline 6076 & 3914 & 32.0 & 29.2 & 1.4 \\
\hline 5720 & 4524 & 34.0 & 31.0 & 1.68 \\
\hline 6810 & 4626 & 50.0 & 47.0 & 2.2 \\
\hline
\end{tabular}

"Load-Load Line Disp." MD050388

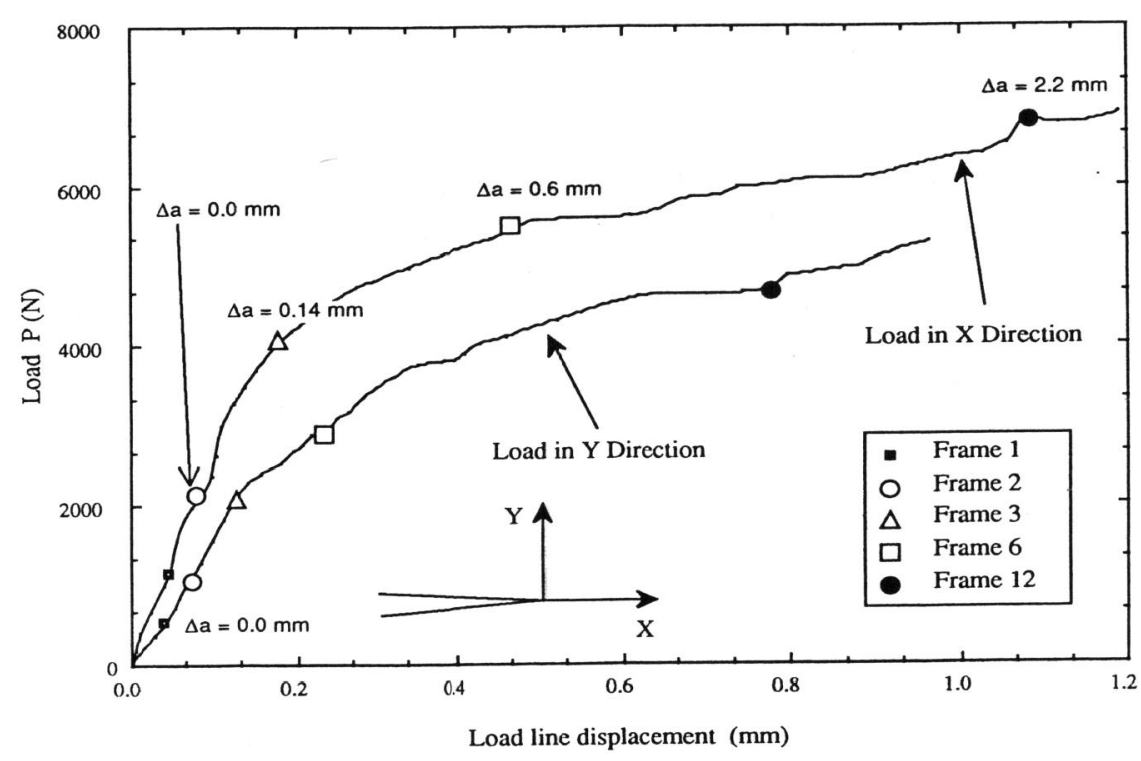

Fig. 3. Load versus Load-line Displacement in 2024-0 Aluminum Specimen, $B \approx 2$.

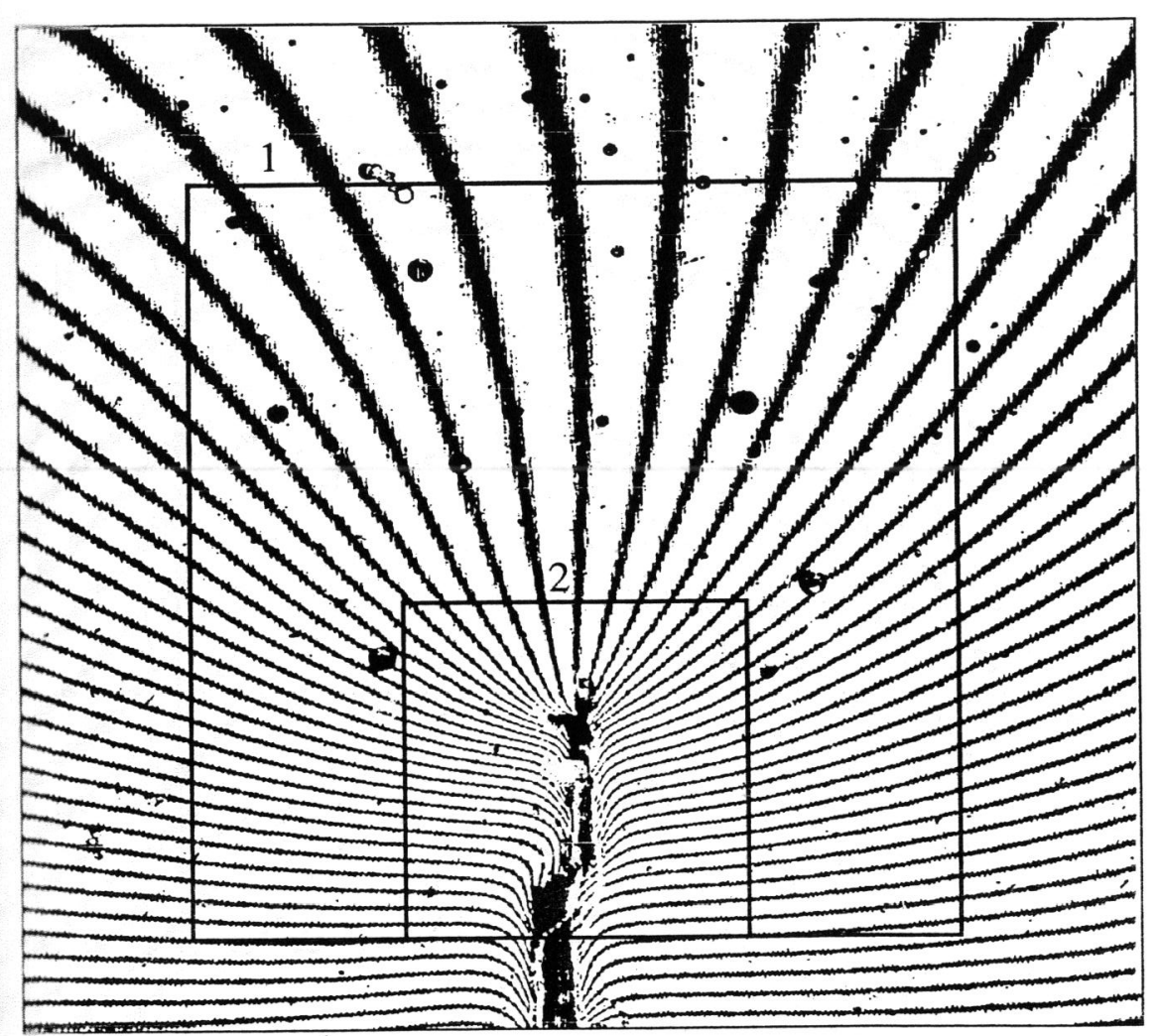

$\longmapsto 5 \mathrm{~mm} \longrightarrow$

Fig. 4a. v-Displacement in 2024-0 Aluminum Specimen, MD050388-3, B $\approx 2.0, \Delta \mathrm{a}=0.14(\mathrm{~mm}), \mathrm{F}_{\mathrm{x}}=4066(\mathrm{~N})$ and $F_{y}=2086(N)$. 


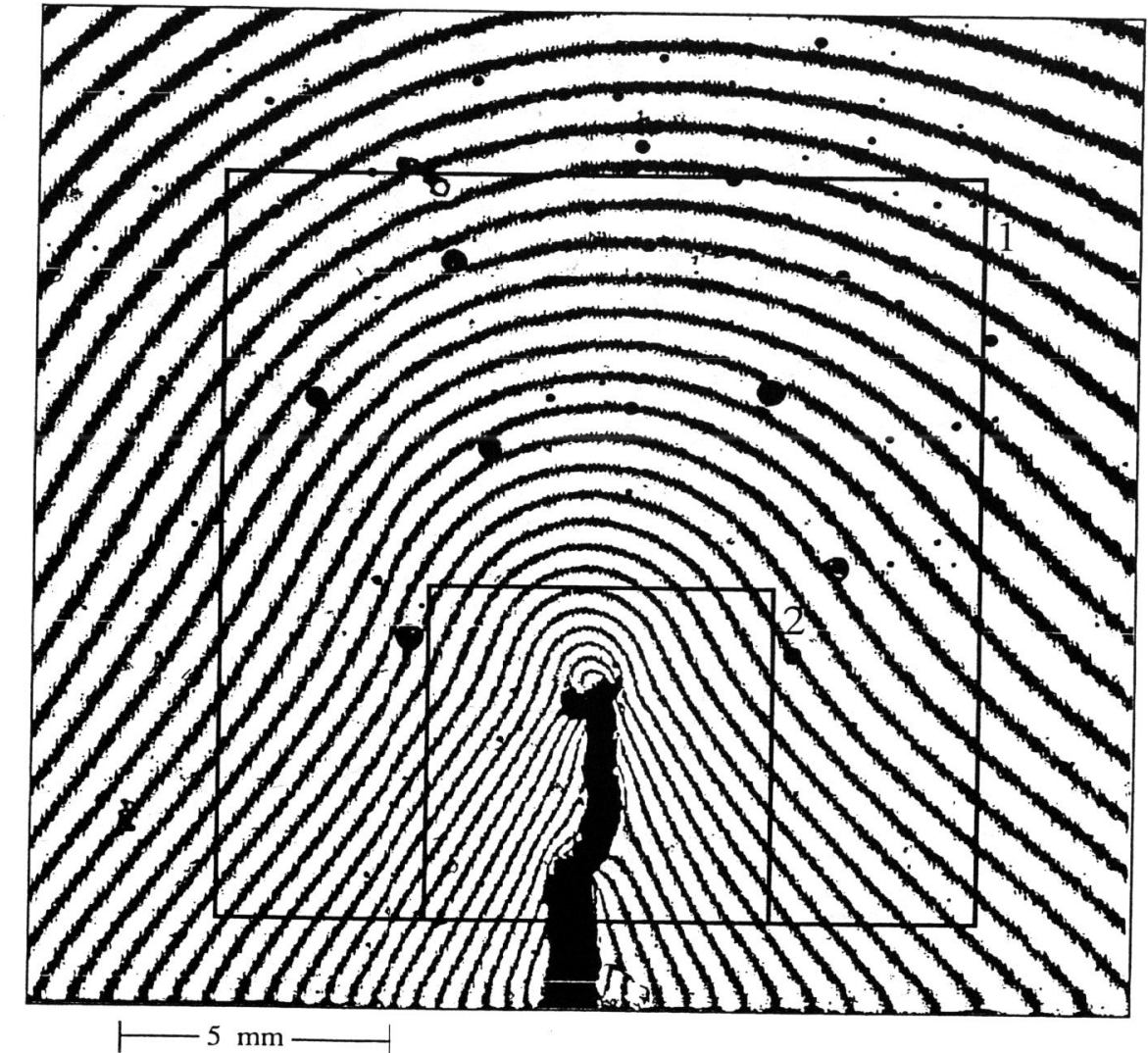

Fig. 4b. u-Displacement in 2024-0 Aluminum Specimen

MD050388-3, $B \approx 2.0, \Delta \mathrm{a}=0.14(\mathrm{~mm}), \mathrm{F}=4066(\mathrm{~N})$ and $F_{y}=2086(N)$.

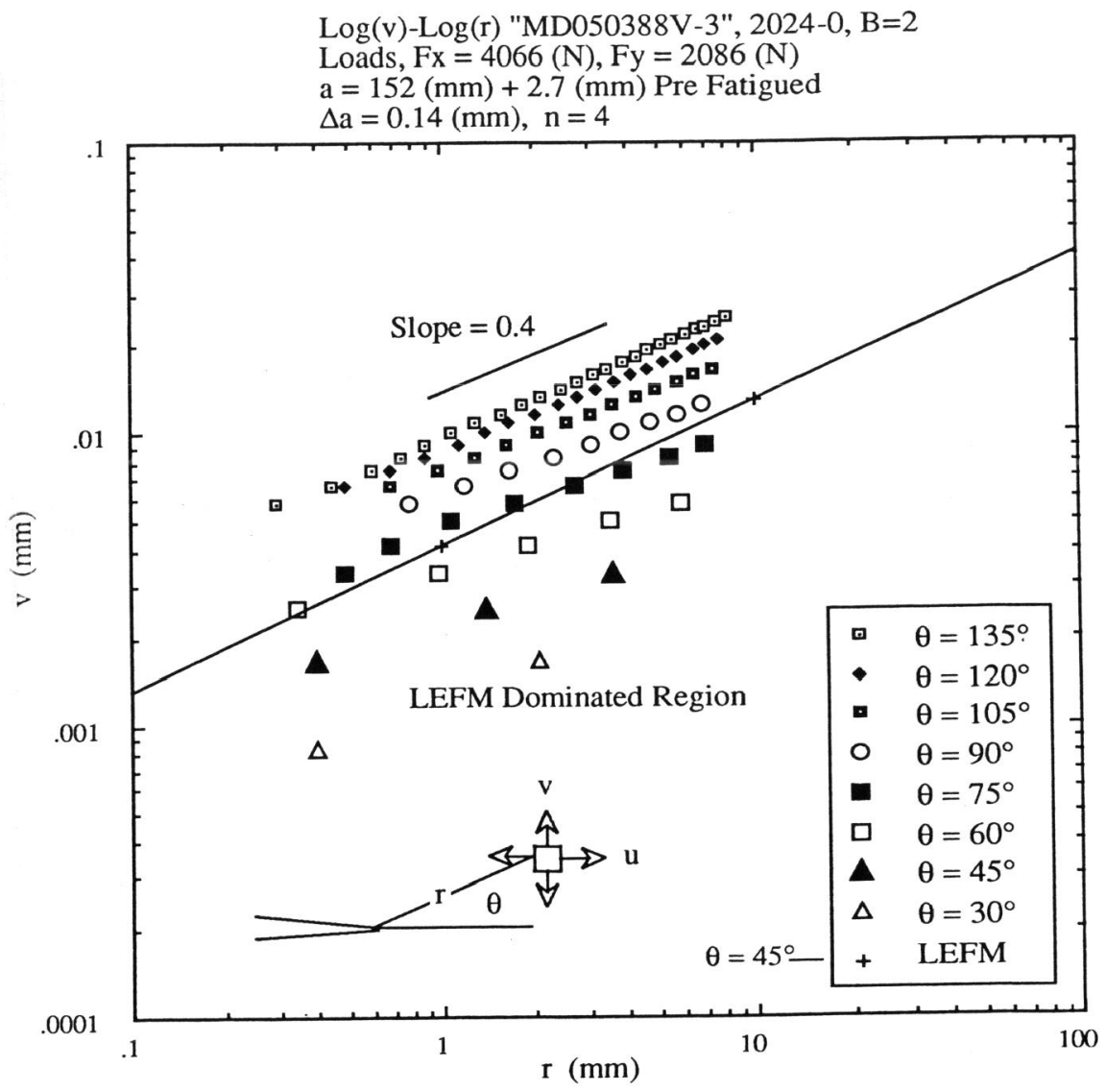

Fig. 5a. v-Displacement Versus $r$ Relation for Various $\theta$, 2024Aluminum MD050388-3 B $\approx 2.0, \Delta \mathrm{a}=0.14 \mathrm{~mm}, \mathrm{~F}_{\mathrm{x}}=$ $4066(\mathrm{~N})$ and $\mathrm{F}_{\mathrm{y}}=2086(\mathrm{~N})$. 
$\log (\mathrm{u})-\log (\mathrm{r})$ "MD050388U-3", 2024-0, B=2

Loads Fx $=4066(\mathrm{~N}), \mathrm{Fy}=2086(\mathrm{~N})$

$\mathrm{a}=152(\mathrm{~mm})+2.7(\mathrm{~mm})$ Pre Fatigued

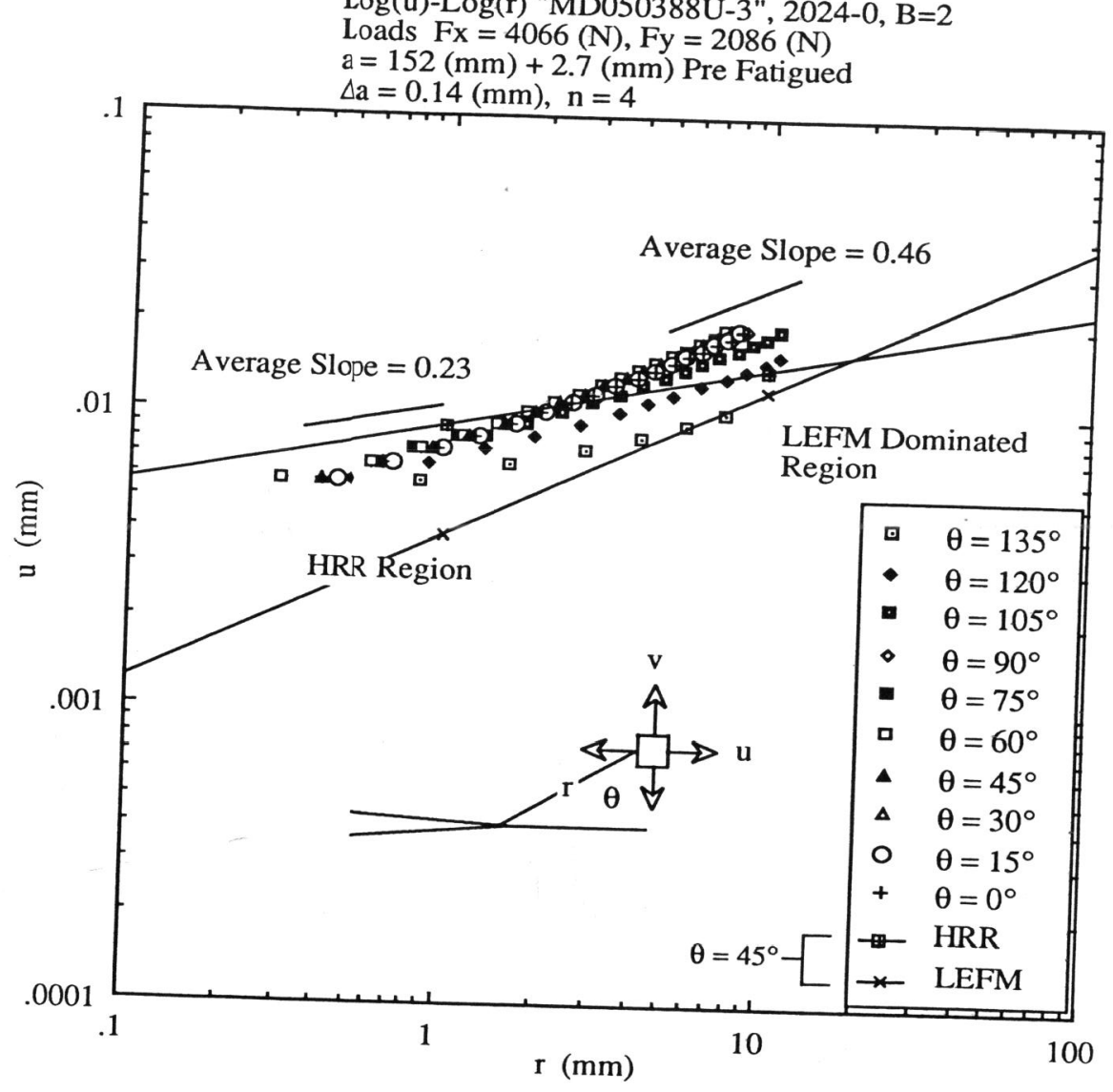

Fig. 5b. u-Displacement Versus $r$ Relation for Various $\theta$, 2024- 0 Aluminum MD050388-3 B $\approx 2.0, \Delta \mathrm{a}=0.14 \mathrm{~mm}, \mathrm{~F}=$ $4066(\mathrm{~N})$ and $\mathrm{F}_{\mathrm{y}}=2086(\mathrm{~N})$.

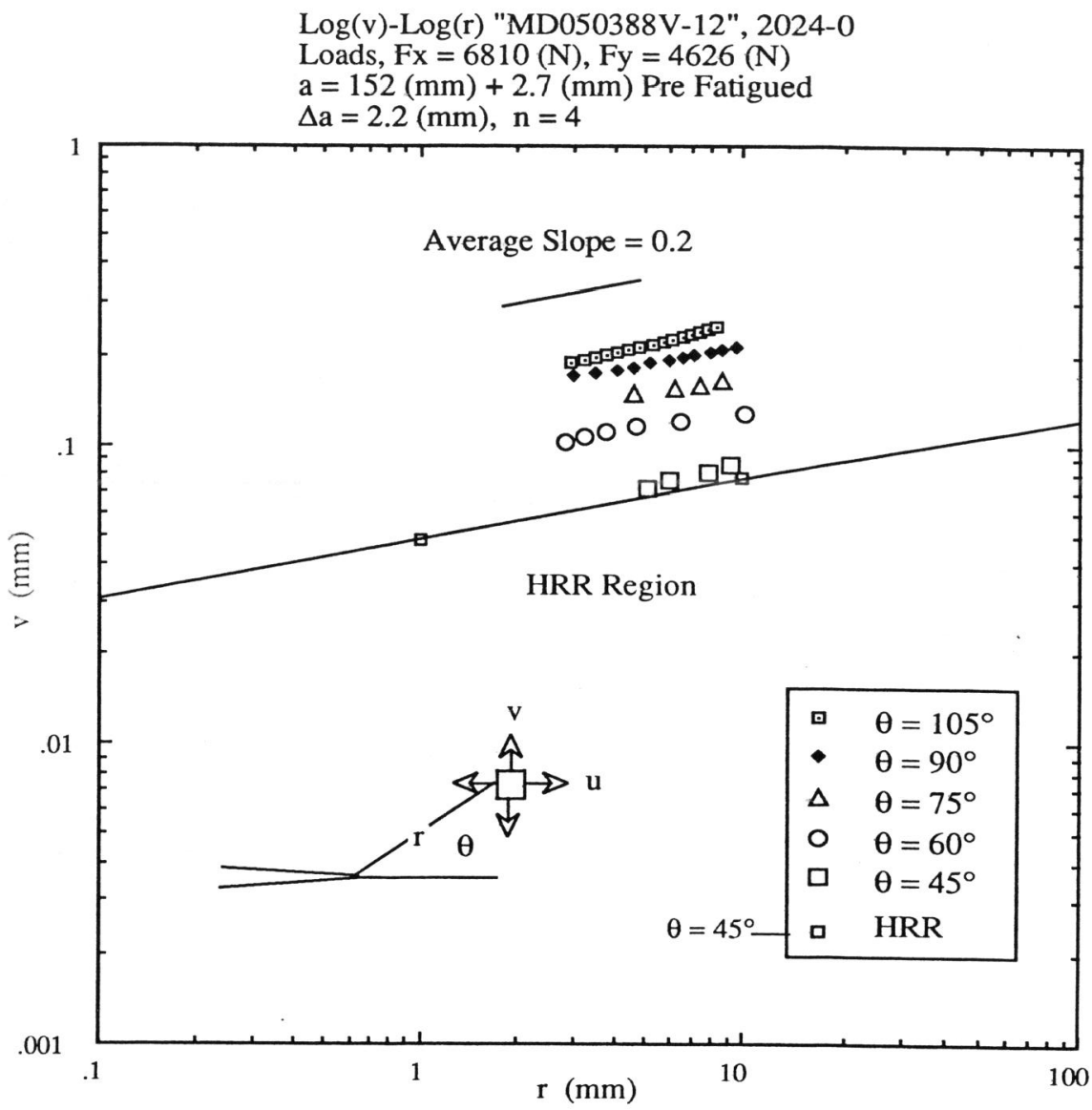

Fig. 6a. v-Displacement Versus $\mathrm{r}$ Relation for Various $\theta$, 2024-0 Aluminum MD050388-12 B $\approx 2.0, \Delta \mathrm{a}=2.2 \mathrm{~mm}, \mathrm{~F}_{\mathrm{x}}=$ $6810(\mathrm{~N})$ and $\mathrm{F}_{\mathrm{y}}=4624(\mathrm{~N})$ 


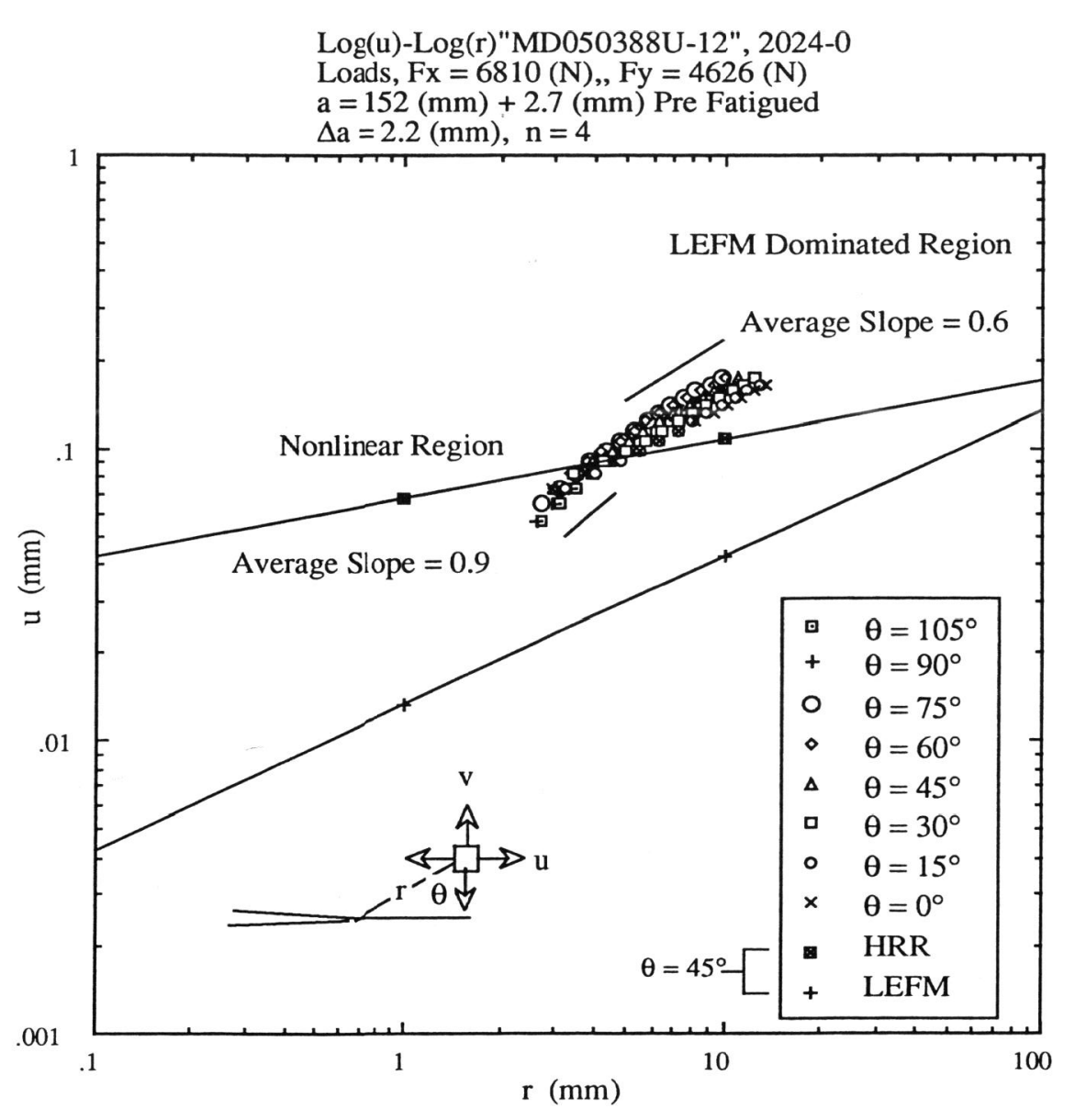

Fig. 6b. u-Displacement Versus $\mathrm{r}$ Relation for Various $\theta$, 2024-0 Aluminum MD050388-12 B $\approx 2.0, \Delta \mathrm{a}=2.2 \mathrm{~mm}, \mathrm{~F}_{\mathrm{x}}=$ $6810(\mathrm{~N})$ and $\mathrm{F}_{\mathrm{y}}=4624(\mathrm{~N})$.
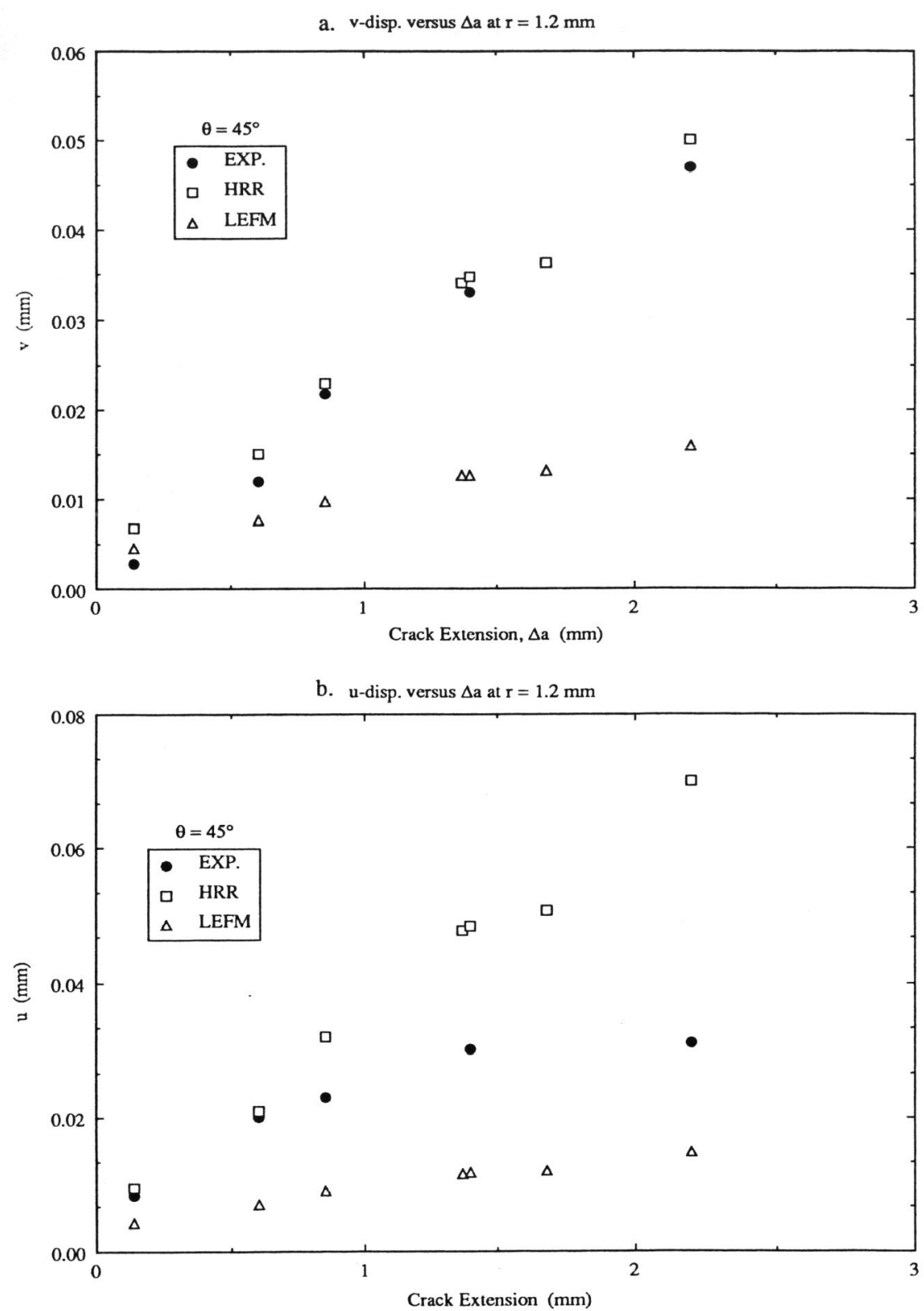

Fig. 7. $\mathrm{v}$ - and $\mathrm{u}$-Displacements at a point of $\mathrm{r}=1.2 \mathrm{~mm}$ and $\theta=$ $45^{\circ}$ versus Crack Extension 


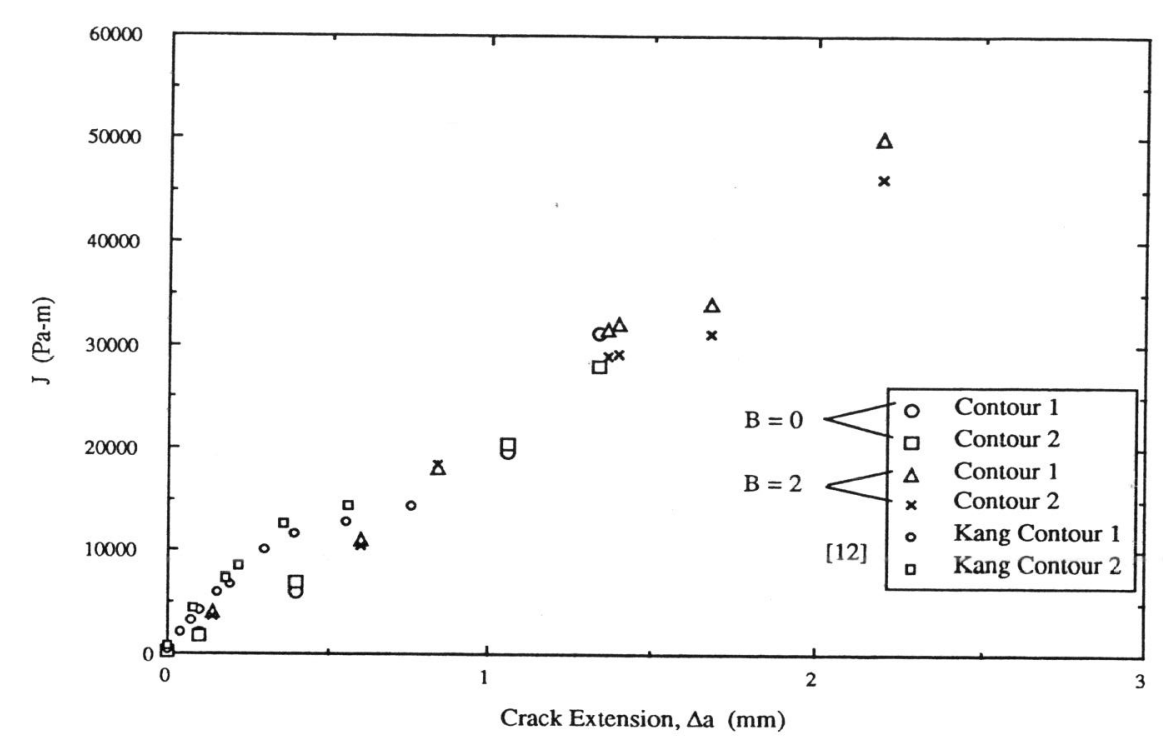

Fig. 8. $J_{R}$ Curve of all 2024-0 Aluminum Tests.

J-resistance curves differ with others in that crack extension occurs at very low applied load and not due to blunting as reported by others (Paris et al, 1979). Fig. 9 shows the J-resistance values for 2024-13 tests during stable crack growth. Also shown is the J-resistance curve of 2-mm and Ernst (1981) for 2024-T351 4T compact tension specimen. The major differnes between the results of the two tests (Hutchinson, 1983) is the knee, which occurred at the lower loads.

\section{DISCUSSION}

The requirements for the $\mathrm{J}$-dominance region for plane strain condition were discussed extensively in the articles by futchinson (1983) and Shih (1985). This present discussion is limited to the analysis of HRR region of a moving crack in plane stress condition. Figure 7 showed that under the same loiding, only the v-field exhibited the expected progression from the LEFM to the HRR crack tip fields. At higher loading where the HRR singularity field should prevail, u-field does no: show any HRR dominated region, but the v-field exhibited a prominent HRR field as shown in Fig. 7. These results indicate that under rapid crack progagation, the desired HRR feld may not exist in ductile materials and thus the dynamically modified $\mathbf{J}$ cannot be used as a fir field parameter to characterize the ductile crack propagation.

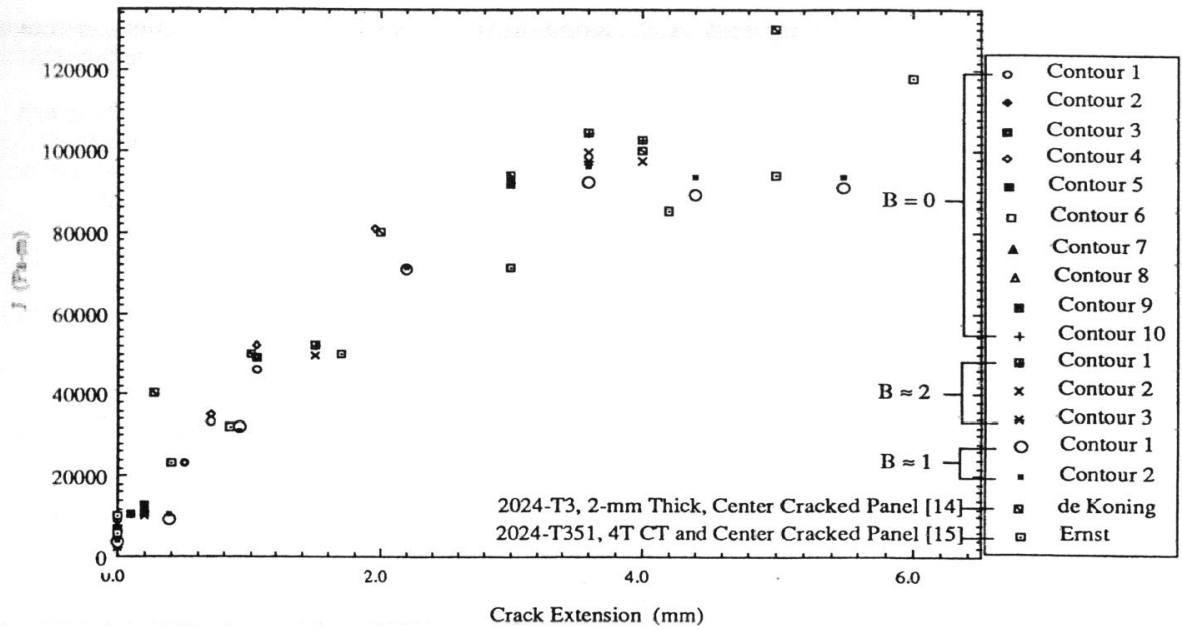

Fig. 9. $J_{R}$ Curve for all 2024-T3 Aluminum Tests of this study, Ref. [14] and [15].

\section{CONCLUSIONS}

1) HRR field exists only during initial loading for u-field and extended up to $2 \mathrm{~mm}$ from the the crack tip.

2) HRR field exist in the v-field through the stable crack growth process and extended up to $10 \mathrm{~mm}$ from the crack tip.

3) $\mathrm{J}$ is path independent for crack extension of $5.6 \mathrm{~mm}$ for 2024-T3 and $2.2 \mathrm{~mm}$ for 2024-0 aluminum alloys.

4) $\mathrm{J}_{\mathrm{R}}$ curves are identical within the scatter of data for 2024-T3 and 2024-0 for both $\mathrm{B}=0$, $\mathrm{B}=1$ and $\mathrm{B}=2$

\section{ACKNOWLEDGEMENT}

This research was sponsored by the Office of Naval Research under ONR Contract No. N00014-85-K-0187. The authors wish to acknowledge the support and encouragement of Dr. $\mathrm{Y}$ apa Rajapakse, ONR, during the course of this investigation.

\section{REFERENCES}

Chiang, F.P. and T.V. Hareesh, (1986). Experimental studies of crack-tip deformation and the HRR singularity field. Proceeding of 1986 SEM Spring Conference on Experimental

Dadkhah, M.S., A.S. Kobayashi, F.X. Wang and D.L. Graesser, (1988). J-integral measurement using moiré interferometry. Proceedings of the VI International Congress on Experimental Mechanics, pp. 227-234. 
Dadkhah, M.S., F.X. Wang and A.S. Kobayashi, (1988). Simultaneous on-line measurement of orthogonal displacement fields by moiré interferometry. Experimental Techniques, $12,28-30$.

de Koning, A.U. (1978). A contribution to the analysis of quasi-static crack growth. Fracture 1977, Proceedings of the 4th International Conference on Fracture, 3A, Pergamon, 25-31. Ernst, H.A., Dec. 3, 1981. Material resistance and instability beyond J-controlled crack growth. Scientific Paper 81-107-JINF-P6, Westinghouse R \& D Center, Pittsburgh, Pa.

Hawong, J.S., A.S. Kobayashi, M.S. Dadkhah, B.S.-J. Kang and M. Ramulu, (1987) $146-153$.

Hutchinson, J.W. (1968). Singular behavior at the end of a tensile crack in a hardening material. Journal of the Mechanics and Physics of Solids, 16, 13-31.

Hutchinson, J.W. (1983). Fundamentals of the phenomenological theory of nonlinear fracture mechanics. Journal of Applied Mechanics, 50 1042-1051.

Kang, B.S.-J., A.S. Kobayashi and D. Post, (1987). Stable crack growth in aluminum tensile specimens. Experimental Mechanics, 27 234-245.

Kang, B.S.-J., A.S. Kobayashi, (1988). J-resistance curves in aluminum SEN specimens. Experimental Mechanics, 28, pp. 154-158.

McMeeking, R.M. and D.M. Parks, (1979). On criteria for J-dominance of crack-tip fields in large-scale yielding. Elastic-Plastic Fracture, ed. by J.D. Landes, J.A. Begley and G.A.

Paris, P.C., H. Tada, A. Zahoor, and H. Ernst, (1979). Elastic-Plastic Fracture, ed. by J.D. Landes, J.A. Begley and G.A. Clarke, The theory of instability of tearing model of elasticplastic crack grow

(he approximate analysis of strain concentration by notches and cracks. ASME Journal of Applied Mechanics, 35, 379-386.

Rice JR and GF. Rosengren, (1968). Plane strain deformation near a crack tip in a powerlaw hardening material. Jourral of the Mechanics and Physics of Solids, 16, 1-12.

hib. CF (1985) J - dome edge crack panel subject to combined tension and bending. International Journal of Fracture, 29. 7384.

Shih C.F and M.D. German, (1981). Requirements for a one parameter characterization of crack tip fields by the HRR singularity. International Journal of Fracture, 17, 27-43.

Shih, C.F., R.G. deLorenzi and W.R. Andrews, (1979). Studies on crack initiation an stable crack growth. Elastic-Plastic Fracture, ed. by J.D. Landes, J.A. Begley and G.A Clarke, ASTM STP $668,65-120$ 